with each of the three other alkali chlorides were sought in preliminary fashion, and evidence was obtained that added sodium chloride causes but little further depression of the freezing point.

[CONTRIBUTION FROM THE DEPARTMENT OF ChEMISTRY OF CORNELL UNIVERSiTy.]

\title{
THE ADSORPTION OF CARBON DIOXIDE AND AMMONIA BY CHARCOAL.
}

BY LEON B. RICHARDSON.

Received June 20, 1917.

The power possessed by charcoal of adsorbing in its pores large volumes of gases was first observed by Scheele, and independently by Fontana, in 1777 . An extensive investigation of the process was made by Saussure $^{1}$ while various phases of the problem were studied by Joulin, ${ }^{2}$ Kayser, ${ }^{3}$ Chappuis, ${ }^{4}$ and Hunter. ${ }^{5}$ The last of these called attention to the superior adsorbing power of cocoanut charcoal, a substance utilized by Dewar many years later for the production of high vacua at the temperature of liquid air. Recently Travers, ${ }^{6}$ Miss Homfray, ${ }^{7}$ and Titoff ${ }^{8}$ have treated the problem with special consideration of equilibrium conditions, and have advanced varied theories as to the nature of the adsorption process.

None of the data in the papers mentioned above extends to pressures beyond the ordinary atmospheric value. It was the object of the work described in the present article to carry the observations in the case of carbon dioxide and of ammonia to pressures of four atmospheres.

\section{Materials and Apparatus.}

The charcoal was prepared by placing fragments of cocoanut shell in an iron tube immersed in a bath of molten antimony, the temperature of which was kept near the melting point $\left(630^{\circ}\right)$. Charcoal prepared at this temperature has been found by Hunter to be most efficient as an adsorbent. Heating for one hour was found to be sufficient to drive off all volatile products. Carbon dioxide was obtained from a cylinder of the liquefied gas known to be of exceptional purity. Upon analysis $99.7 \%$ of the total volume taken was absorbed by a solution of sodium hydroxide. Ammonia was obtained from a cylinder of the liquid, the purity of which had been tested by previous work in this laboratory. The vapor pressure

1 Gilb, Ann., 47, II3 (1814).

2 Ann. chim. phys., 22, 397 (1881).

${ }^{3}$ Ann. Phys., [3] 12, 526 (1881).

4 Ibid., [3] 12, 160 (1881).

5 Phil. Mag., 25, 364 (1863); 29, I16; J. Chem. Soc., 18, 285 (1865); 20, 160 (1867); 21, I $86(1868) ; 23,73$ (1870); 24, 769 (1871); 25, 649 (1872).

${ }^{6}$ Proc. Roy. Soc., 78A, 9 (1906).

${ }^{7}$ Z. physik. Chem., 74, 129 (1910).

8 Ibid., 74, 641 (1910). 
of this liquid determined in the apparatus used in this work coincided with the known vapor pressure of pure liquid ammonia.

The apparatus was somewhat similar to that employed by Browne and Houlehan ${ }^{1}$ in the investigation of the system ammonium trinitride, ammonia. In perfected form it has since been used in a number of investigations in this laboratory. A sketch of the essential parts is given in Fig. I. Cell $C$ containing the charcoal is connected on one side with the mercury $M$ manometer $M$, capable of registering pressures up to four atmos pheres; and on the other, through the two-way stopcock $H$, with the Ioo cc. waterjacketed gas buret $A$. The connecting tubing is of one $\mathrm{mm}$. bore. Gas enters the apparatus at $E$, having been dried in the case of carbon dioxide by bubbling through two Muencke wash bottles containing sulfuric acid, and in the case of ammonia by passing through a tube

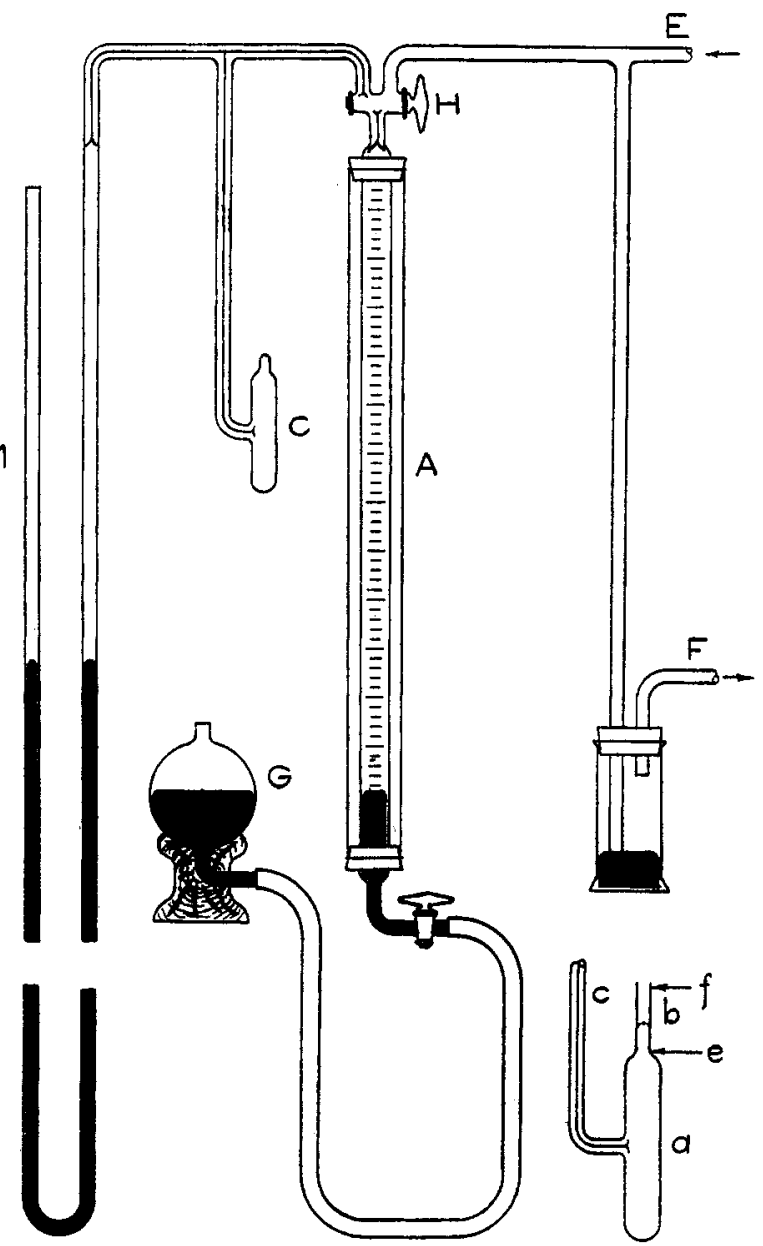

Fig. 1.

$20 \mathrm{~cm}$. long containing sodium wire. Exit is through the mercury $\operatorname{trap} F$. No rubber connections were used in the apparatus: all joints were made by fusing together the tubing. By manipulation of the stopcock $H$ and the leveling bulb $G$ gas could be pumped out of the cell and manometer and expelled through $F$ until a Torricellean vacuum was obtained. Gas could then be drawn in through $E$, its volume measured in

1 This Journal, 33, I 742 (I9II). 
the buret under known temperature and pressure conditions, and introduced into the cell.

The calibration of the manometer was carried out both with carbon dioxide and with ammonia. A cell of known capacity containing no charcoal was fused in place and measured volumes of gas were forced into the system until the maximum pressure to be recorded in these experiments was reached. The temperature of the cell was maintained at $0^{\circ}$, gas was withdrawn in measured portions and manometer readings taken after each withdrawal until all was removed. The volume of gas in cell and manometer at each recorded pressure was thus obtained. The volume of gas in the cell at each of these pressure points was obtained by calculation: the latter values subtracted from the former gave the volume of gas in the manometer at each pressure. From these figures a manometer calibration curve was drawn. All volumes mentioned above were, of course, volumes under standard conditions of pressure and temperature.

In the experiments with carbon dioxide equilibrium pressures were measured at twenty-one temperature points between $-64^{\circ}$ and $200^{\circ}$; in those with ammonia at seventeen points between $-20^{\circ}$ and $200^{\circ}$. For points below the room temperature the cell was immersed in mixtures of solid carbon dioxide and alcohol contained in a Dewar flask; from that point to $100^{\circ}$ by using as a bath a beaker containing 2.5 liters of water heated by a Bunsen burner; from $100^{\circ}$ to $200^{\circ}$ by using a bath of paraffin heated in the same way. All baths were stirred by a rapidly rotating spiral of glass tubing.

Such methods of temperature regulation are to be criticized on account of the attention required in their use rather than on account of their lack of accuracy. No difficulty was experienced in maintaining the temperature of mixtures of solid carbon dioxide and alcohol constant to O.I ${ }^{\circ}$, by the periodic addition of small quantities of the solid. Relatively large volumes of water, efficiently stirred, were kept within $0.2^{\circ}$ of the desired point by hand regulation of a burner, although the operation requires attention and experience. The paraffin bath was found most difficult of the three to control, but even here the maximum variation was $0.5^{\circ}$; in most cases it was much less. The conditions of the experiment were not such as to require "greater accuracy of temperature regulation than is shown by the data above.

Four thermometers were used: three of mercury and one of pentane. They were compared with each other and with standard thermometers of known accuracy.

The specific gravity of an air-free sample of the charcoal used was determined in the following manner: A cell containing a convenient quantity was fused to the apparatus just described, was evacuated and was 
then heated to $400^{\circ}$ in an electrical resistance furnace. The adsorbed gas was slowly liberated at this temperature, and was pumped out of the apparatus as fast as it was given off. When the gas was all removed, a process which required eight hours, the cell was sealed off, care being taken to preserve the vacuum, was weighed and the sealed tip was broken off under boiling water, which rushed in, filling the cell and the pores of the charcoal. After cooling, the cell was broken cleanly in the middle, the wet charcoal was placed in a pycnometer, and the usual procedure was followed. The weight of the dried fragments of the glass of the cell was ascertained; the two halves were calibrated and their air capacity calculated. For these values the specific gravity of the charcoal was determined. The mean of two closely concordant determinations was found to be 1.60 .

The sample of charcoal used in the determinations was composed of pieces of nearly uniform size $(5 \mathrm{~mm}$.). Its weight in an air-free condition, obtained by a method similar to that described in the preceding paragraph, was found to be $2.2414 \mathrm{~g}$. The volume was therefore $1.40 \mathrm{cc}$. At the conclusion of the experiments the charcoal was burned and the ash content found to be $0.0396 \mathrm{~g}$. The weight of the ash-free charcoal was thus $2.2018 \mathrm{~g}$.

The cell was constructed in the form shown in the insert in Fig. I. Tube $a$ has an internal diameter of $10 \mathrm{~mm}$., tube $b 5.5 \mathrm{~mm}$., and tube $c$ I mm. The capacities of the cell to the marks $e$ and $f$, of known distance apart, were separately determined. The weighed sample of charcoal was then introduced through $b$, and that tube was fused off at a point between $e$ and $f$, taking care to make the conical termination as nearly regular as possible. Measurement was then made of the distance between the mark $e$ and the base of this cone; from this value the capacity of the remainder of tube $b$ up to the cone could be determined. A number of cones were then made from another piece of tube $b$ and their volumes determined, giving values in very close agreement. The mean value was taken as the volume of the cone in the cell. The total volume of the cell, the sum of the three separate measurements (volume to $e+$ volume from $e$ to the base of the cone + volume of the cone), was found to be $7.7 \mathrm{I} \mathrm{cc}$. Deducting the volume of the charcoal the free space in the cell was thus $6.3 \mathrm{I} \mathrm{cc}$.

\section{Method of Procedure.}

The method of procedure applied in the determinations was as follows: The cell containing the weighed sample of charcoal was sealed to the apparatus and the air was removed by the method already indicated. A measured quantity of carbon dioxide was introduced from the buret and was allowed to remain in contact with the charcoal overnight. The next morning the temperature was lowered to a point $\left(-70^{\circ}\right)$ below that, 
at which the first reading was to be taken, and was kept in that vicinity for from one to two hours. The temperature was then allowed to rise to $-64^{\circ}$ and was kept carefully at this point, the mercury levels being read every five minutes. Equilibrium was considered to have been attained when the pressure remained constant for twenty minutes, a process which required from thirty minutes to two hours. Temperature corrections were applied both to barometric and manometric readings. The temperature was then allowed to rise slowly to the next point, and the process repeated. When values had been obtained in this way for each of the twenty-one points in the temperature range a fresh quantity of gas was introduced and the measurements of another series were obtained.

It has been the experience of previous investigators that the equilibrium between free and adsorbed gas is quickly attained. In general this was found to be true in the present investigation if conditions under which the equilibrium was determined were parallel. In the course of the work, however, certain abnormalities developed, which are not without interest from a theoretical viewpoint.

In the first place it was found to be impossible to secure accurate equilibrium values from volumes of gas just introduced into system. When attempts were made to determine the equilibrium pressure at $-64^{\circ}$ directly after a new quantity of gas had been admitted to the charcoal, it was found that the mercury levels in the manometer were subject to such fluctuations as to make attainment of constant values in any reasonable time impossible. When, however, the gas was allowed to stand overnight at room temperature, in contact with the charcoal, no such difficulty was experienced. It was evident that some slow process was at work which had to do with the adsorption by charcoal of gaseous molecules just brought into contact with that substance.

In the second place, pressure values obtained at a definite point of temperature low in the scale in a system in which the temperature was falling were not coincident with those at that point in the same system in which the temperature was rising, although both pressures were constant in themselves. Thus about $150 \mathrm{cc}$. of carbon dioxide were admitted to the charcoal, the mixture was allowed to stand overnight, the temperature was then slowly lowered to $-30^{\circ}$ and was kept at that point, after equilibritum seemed to have been attained, for three hours, pressure readings being taken every fifteen minutes. The temperature of the cell was then lowered to $-70^{\circ}$, was kept at that point for one hour, and was then slowly raised to $-30^{\circ}$. Here it was kept for three and a half hours, the pressure readings being taken every fifteen minutes as before. The mean value of the eleven pressure readings at $-30^{\circ}$, obtained when that temperature was approached from above (Series I), was $28.79 \mathrm{~cm}$., 
with a maximum deviation of $0.1 \mathrm{~cm}$.; the mean of the twelve pressure readings at the same temperature point approached from below (Series 2) was $25.05 \mathrm{~cm}$., with the same maximum deviation. While the differences in the pressure values in the same series were no greater than might be expected from slight variations of the temperature of the bath, the difference between the mean pressure values of the two series, values measured under conditions which were supposedly identical, was marked. If now the temperature was raised to $20^{\circ}$ and again lowered to $-30^{\circ}$ the pressure observed was once more in close agreement with the mean value of Series I; if the lowering was continued to $-70^{\circ}$ and the temperature was then brought back to $-30^{\circ}$ the pressure became that of Series 2 . Each value was thus readily reproducible, and two temperature-pressure curves could be obtained for each gas volume, one representing values on a descending temperature, the other on a rising one. These curves approached as temperatures became higher and finally met at about $55^{\circ}$, above which point the pressure values obtained either way were the

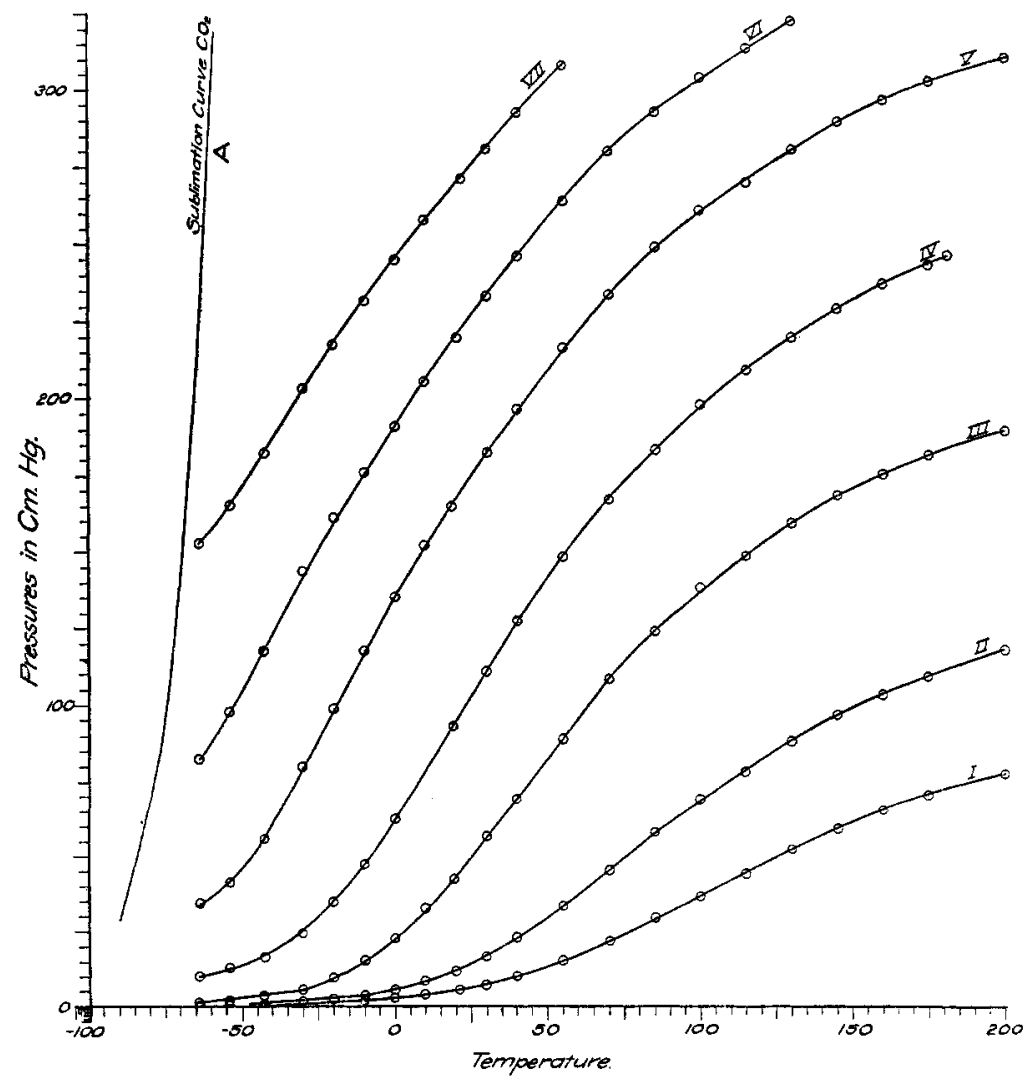

Fig. 2. 
same. In practice, therefore, the pressure readings were always taken under the same conditions, $i$. e., on a rising temperature. These abnormalities will be given further consideration in a following section of this paper.

\section{Experimental Data.}

The values obtained in the experiments with carbon dioxide are given below. In the first column are recorded the temperature points, in the second pressures in centimeters of mercury. The third column contains the total volume of carbon dioxide in the gaseous phase; the sum of the volume of the gas in the manometer, read from the calibration curve, and of the volume of free gas in the cell, calculated from the free space of the cell and the known temperature and pressure conditions. Col. 4 records the differences between the total gas introduced and the values in Col. 3 ; it represents, therefore, the total volume of gas adsorbed in the charcoal. Col. 5 gives volume of gas adsorbed per gram of ash-free charcoal.

\begin{tabular}{|c|c|c|c|c|}
\hline \multirow[b]{2}{*}{ Temp. } & \multirow[b]{2}{*}{ Press. cm, Hg. } & \\
\hline & & $\begin{array}{l}\text { In vapor } \\
\text { phase. }\end{array}$ & $\begin{array}{c}\text { Total } \\
\text { absorbed. }\end{array}$ & \multirow[t]{2}{*}{$\begin{array}{l}\text { Adsorbed } \\
\text { per g. C. }\end{array}$} \\
\hline & Series I. Vol. & $\mathrm{CO}_{2}$ in $\mathrm{Sy}$ & $25.8 \mathrm{cc}$ & \\
\hline-30 & 0.7 & 0.3 & $25 \cdot 5$ & II. 6 \\
\hline-20 & I. I & 0.4 & $25 \cdot 4$ & II. 6 \\
\hline-10 & 1.7 & 0.5 & $25 \cdot 3$ & II. 5 \\
\hline 0 & 2.4 & 0.7 & 25.1 & II. 4 \\
\hline IO & 3.6 & 1.0 & 24.8 & II. 3 \\
\hline 21.4 & $5 \cdot 3$ & 1.4 & $24 \cdot 4$ & II.I \\
\hline 30 & $7 \cdot 3$ & I. 8 & 24.0 & 10.9 \\
\hline 40 & 9.9 & 2.5 & 23.3 & 10.6 \\
\hline 55 & I5.I & 3.8 & 22.0 & 10.0 \\
\hline 70 & $2 I .7$ & $5 \cdot 5$ & 20.3 & 9.2 \\
\hline 85 & 29.2 & $7 \cdot 4$ & 18.4 & 8.3 \\
\hline 100 & 36.8 & 9.6 & 16.2 & $7 \cdot 4$ \\
\hline II 5 & $44 \cdot 4$ & 12.0 & 13.8 & 6.3 \\
\hline I30 & 52,2 & I 4.6 & II .2 & $5 . I$ \\
\hline$I_{45}$ & 59.2 & 16.9 & 8.9 & $4 \cdot I$ \\
\hline 160 & $65 \cdot 5$ & 18.9 & 6.9 & $3 \cdot 1$ \\
\hline 175 & 70.7 & 21.0 & 4.8 & 2.2 \\
\hline 200 & 77.7 & 23.7 & $2 . I$ & 1.0 \\
\hline
\end{tabular}

Series II. Vol. of $\mathrm{CO}_{2}$ in System, $48 . \mathrm{I}$ cc.

$\begin{array}{rrrrr}-43 & 0.6 & 0.2 & 47.9 & 21.8 \\ -30 & 1.2 & 0.4 & 47.7 & 21.7 \\ -20 & 2.2 & 0.6 & 47.5 & 21.6 \\ -10 & 3.6 & 1.1 & 47.0 & 21.4 \\ 0 & 5.4 & 1.6 & 46.5 & 21.2 \\ 10 & 8.4 & 2.3 & 45.8 & 20.9 \\ 20.6 & 11.9 & 3.2 & 45.0 & 20.5 \\ 30 & 16.8 & 4.4 & 43.7 & 19.9 \\ 40 & 23.0 & 6.5 & 41.6 & 19.0\end{array}$


ADSORPTION OF CARBON DIOXIDE AND AMMONLA BY CHARCOAL, I835

\begin{tabular}{|c|c|c|c|c|}
\hline \multirow{3}{*}{ Temp. } & \multirow{3}{*}{$\begin{array}{r}\text { Press. cm. Hg. } \\
\text { Series }\end{array}$} & \multicolumn{3}{|c|}{ 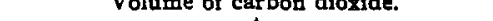 } \\
\hline & & & $\begin{array}{c}\text { Total } \\
\text { adsorbed. }\end{array}$ & \multirow[t]{2}{*}{$\begin{array}{l}\text { Adsorbed } \\
\text { per g. C. }\end{array}$} \\
\hline & & II (contin & & \\
\hline 55 & 33.7 & 9.5 & 38.6 & 17.6 \\
\hline 70 & 45.8 & 12.8 & $35 \cdot 3$ & 16.1 \\
\hline 85 & 58.1 & I 7.4 & 30.7 & 15.0 \\
\hline 100 & 69.3 & 21.0 & $27 . I$ & 12.3 \\
\hline II 5 & 78.8 & 24.9 & 23.2 & 10.5 \\
\hline 130 & 88.6 & 29.4 & 18.7 & 8.5 \\
\hline I 45 & $97 \cdot I$ & 33.0 & I5.I & 6.9 \\
\hline 160 & 103.9 & 36.2 & II.9 & $5 \cdot 4$ \\
\hline I 75 & 109.7 & 38.8 & 9.3 & 4.2 \\
\hline 200 & II $8 . I$ & 42.6 & $5 \cdot 5$ & 2.5 \\
\hline
\end{tabular}

Series III. Vol. of $\mathrm{CO}_{2}$ in System, 97.I cc.

$\begin{array}{rrrrr}-64 & 1.3 & 0.5 & 96.6 & 43.9 \\ -54 & 2.0 & 0.6 & 96.5 & 43.9 \\ -43 & 3.2 & 0.9 & 96.2 & 43.7 \\ -30 & 5.8 & 1.6 & 95.5 & 43.4 \\ -20 & 9.3 & 2.5 & 94.6 & 43.0 \\ -10 & 15 . I & 4.1 & 93.0 & 42.3 \\ 0 & 22.6 & 6.2 & 90.9 & 41.3 \\ 10 & 32.3 & 8.8 & 88.3 & 40.1 \\ 20 & 42.6 & 12.3 & 84.8 & 38.5 \\ 30 & 56.3 & 17.0 & 80.1 & 36.4 \\ 40 & 69.7 & 22.0 & 75.1 & 34 . I \\ 55 & 89.6 & 31.0 & 66.1 & 30.1 \\ 70 & 109.1 & 40.2 & 56.9 & 25.9 \\ 85 & 124.4 & 47.8 & 49.3 & 22.4 \\ 100 & 138.5 & 55.5 & 41.6 & 18.9 \\ 115 & 149.3 & 61.5 & 35.6 & 16.2 \\ 130 & 159.8 & 68.2 & 28.9 & 13.1 \\ 145 & 168.8 & 73.7 & 23.4 & 10.6 \\ 160 & 175.7 & 78.0 & 19.1 & 8.7 \\ 175 & 181.9 & 81.8 & 15.3 & 6.9 \\ 200 & 189.5 & 86.9 & 10.2 & 4.6\end{array}$

Series IV. Vol. $\mathrm{CO}_{2}$ in System, $143.7 \mathrm{cc}$.

$\begin{array}{crrrr}-64 & 10.0 & 2.8 & 140.9 & 64.1 \\ -54 & 12.6 & 3.7 & 140.0 & 63.6 \\ -43 & 16.6 & 4.6 & 139.1 & 63.2 \\ -30 & 24.7 & 6.9 & 136.8 & 62.2 \\ -20 & 35.6 & 9.9 & 133.8 & 60.9 \\ -10 & 47.4 & 14.4 & 129.3 & 58.8 \\ 0 & 62.6 & 19.9 & 123.8 & 56.3 \\ 19.5 & 93.7 & 33.9 & 109.8 & 49.9 \\ 30 & 111.7 & 44.6 & 99.1 & 45.1 \\ 40 & 127.7 & 51.5 & 92.2 & 41.9 \\ 55 & 148.9 & 63.0 & 80.7 & 36.8 \\ 70 & 167.7 & 75.0 & 68.7 & 31.2 \\ 85 & 184.0 & 85.6 & 58.1 & 26.4\end{array}$


Volume of carbon dioxide.

$\begin{array}{lcccr}\text { Temp. } & \text { Press. cm. Hg. } & \begin{array}{c}\text { In vapor } \\ \text { phase. }\end{array} & \begin{array}{c}\text { Total } \\ \text { adsorbed. }\end{array} & \begin{array}{c}\text { Adsorbed } \\ \text { per g. C. }\end{array} \\ \text { I00 } & \text { Series IV (continued) }) & & \\ 115 & 198.1 & 95.7 & 48.0 & 21.8 \\ 130 & 209.3 & 103.9 & 39.8 & 18.1 \\ 145 & 219.8 & 111.6 & 32.1 & 14.6 \\ 160 & 229.1 & 119.3 & 24.4 & 11.1 \\ 175 & 237.3 & 126.8 & 16.9 & 7.7 \\ 181 & 243.9 & 132.0 & 11.7 & 5.3 \\ & 246.4 & 134.2 & 9.5 & 4.3\end{array}$

Series V. Vol. $\mathrm{CO}_{2}$ in System, 204.2 ce.

$\begin{array}{rrrrr}-64 & 34.8 & 10.6 & 193.6 & 88.0 \\ -54 & 41.3 & 12.4 & 191.8 & 87.2 \\ -43 & 56.0 & 18.2 & 186.0 & 84.5 \\ -30 & 80.3 & 28.1 & 176.1 & 80.0 \\ -20 & 99.1 & 37.6 & 166.6 & 75.7 \\ -10 & 117.9 & 47.9 & 156.3 & 71.0 \\ 0 & 135.7 & 57.1 & 147.1 & 66.9 \\ 10 & 152.7 & 67.2 & 137.0 & 62.3 \\ 20 & 165.3 & 75.3 & 128.8 & 58.6 \\ 30 & 183.0 & 86.7 & 117.5 & 53.4 \\ 40 & 197.0 & 97.6 & 106.6 & 48.4 \\ 55 & 217.0 & 112.4 & 91.8 & 41.7 \\ 70 & 234.2 & 126.7 & 77.5 & 35.2 \\ 85 & 249.5 & 140.6 & 63.6 & 28.9 \\ 100 & 261.7 & 150.0 & 54.2 & 24.6 \\ 115 & 270.2 & 157.9 & 46.3 & 21.0 \\ 130 & 281.2 & 168.6 & 35.6 & 16.2 \\ 145 & 290.2 & 176.8 & 27.4 & 12.5 \\ 160 & 297.7 & 185.1 & 19.1 & 8.7 \\ 175 & 303.8 & 192.0 & 12.2 & 5.5 \\ 200 & 311.5 & 200.9 & 3.3 & 1.5\end{array}$

Series VI. Vol. $\mathrm{CO}_{2}$ in System, $256.1 \mathrm{cc}$.

$\begin{array}{rrrrr}-64 & 82.9 & 31.0 & 225.1 & 102.3 \\ -54 & 97.9 & 38.4 & 217.7 & 99.0 \\ -43 & 117.9 & 48.8 & 207.3 & 94.2 \\ -30 & 143.8 & 63.4 & 192.7 & 87.6 \\ -20 & 161.3 & 74.5 & 181.6 & 82.7 \\ -10 & 176.4 & 84.6 & 171.5 & 77.9 \\ 0 & 191.4 & 95.1 & 161.0 & 73.2 \\ 10 & 206.7 & 106.4 & 149.7 & 68.0 \\ 20.6 & 220.0 & 116.8 & 139.3 & 63.3 \\ 30 & 233.8 & 127.6 & 128.5 & 58.4 \\ 40 & 246.6 & 139.8 & 116.3 & 52.8 \\ 55 & 264.2 & 155.6 & 100.5 & 45.7 \\ 70 & 280.7 & 171.0 & 85.1 & 38.7 \\ 85 & 293.5 & 183.6 & 72.5 & 32.9 \\ 100 & 304.9 & 195.9 & 69.2 & 27.3 \\ 115 & 314.5 & 208.2 & 48.9 & 22.2 \\ 130 & 323.7 & 220.0 & 36.1 & 16.4\end{array}$




\begin{tabular}{|c|c|c|c|c|}
\hline \multirow[b]{2}{*}{ Temp. } & \multicolumn{4}{|c|}{ Volume of carbon dioxide. } \\
\hline & Press. cm. & $\begin{array}{c}\text { In vapor } \\
\text { phase. }\end{array}$ & $\begin{array}{c}\text { Total } \\
\text { adsorbed. }\end{array}$ & $\begin{array}{l}\text { Adsorbed } \\
\text { per g. C. }\end{array}$ \\
\hline & Series VII. & Vol. $\mathrm{CO}_{2}$ in $\mathrm{Sy}$ & $1,307.6 \mathrm{cc}$. & \\
\hline-64 & 153.0 & 71.9 & 235.7 & $107 \cdot x$ \\
\hline-54 & I65.6 & 79.4 & 228.2 & I03. 7 \\
\hline-43 & 182.4 & 91.0 & 216.6 & 98.5 \\
\hline-30 & $203 \cdot 5$ & 106.6 & 201,0 & 91.4 \\
\hline-20 & 217.8 & 117,7 & 189.9 & 86.3 \\
\hline-10 & 23 I. 8 & 129.3 & 178.3 & 81.0 \\
\hline 0 & $245 \cdot I$ & I4I.I & 166.5 & 75.7 \\
\hline 10 & 258.0 & 152.2 & I 55.2 & 70.6 \\
\hline 22 & 271.9 & $165 \cdot 3$ & 142.3 & 64.7 \\
\hline 30 & $28 \mathrm{r} \cdot 5$ & 171.7 & 135.9 & $61: 8$ \\
\hline 40 & 293.2 & I86. I & $12 \mathrm{I} .5$ & 55.2 \\
\hline 55 & 308.9 & 201.2 & 106.4 & 48.4 \\
\hline
\end{tabular}

The pressure-temperature curves of the seven series are given in Fig. 2. Each represents conditions for definite quantities of carbon dioxide in the solid and vapor phases combined. It will be noted that the curves are spaced rather uniformly, and are not grouped together in any particular region of the field. The flattening at the top is due to the relative exhaustion of the solid phase; that at the bottom to the exhaustion of the vapor phase. The sublimation curve of carbon dioxide from the data of Zeleny and Smith $^{1}$ is given for purposes of comparison. The isotherms are shown in Fig. 3.

\section{Ammonia.}

The same cell and charcoal were used in the experiments with ammonia. Care was taken to remove the carbon dioxide completely before starting the second group of determinations. The experimental data follow:

$$
1 \text { Phys. Z., 7, } 667 \text { (1906). }
$$

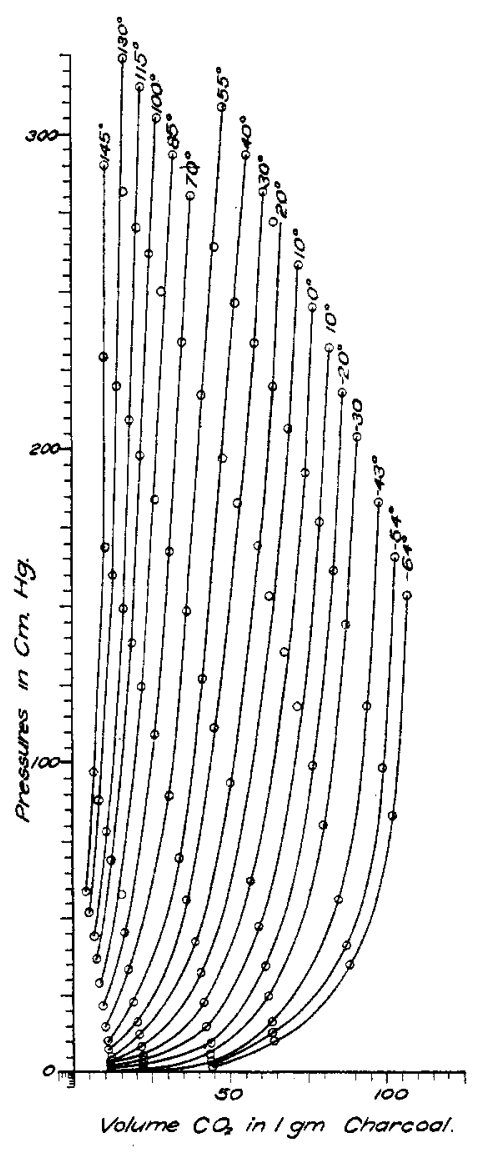

Fig. 3 . 


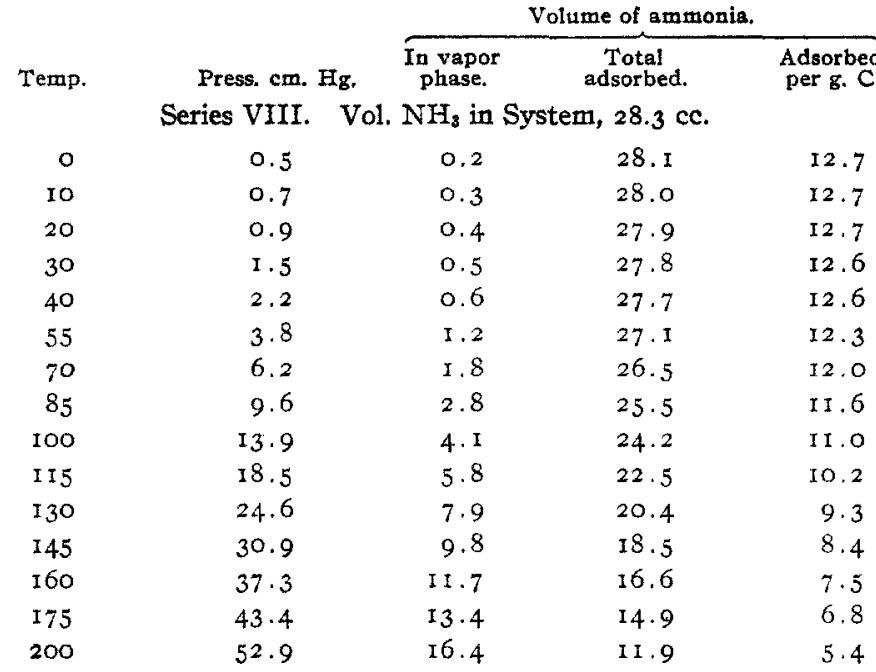

Series IX. Vol. $\mathrm{NH}_{3}$ in System, $57.5 \mathrm{cc}$.

$\begin{array}{rrrrr}\text {-20 } & 0.6 & 0.3 & 57.2 & 26.0 \\ \text {-10 } & 1.1 & 0.4 & 57.1 & 25.9 \\ 0 & 1.7 & 0.5 & 57.0 & 25.9 \\ 10 & 2.5 & 0.8 & 56.7 & 25.8 \\ 19 & 3.5 & 1.1 & 56.4 & 25.6 \\ 30 & 5.4 & 1.6 & 55.9 & 25.4 \\ 40 & 8.3 & 2.5 & 55.0 & 25.0 \\ 55 & 14.0 & 4.3 & 53.2 & 24.1 \\ 70 & 22.1 & 7.3 & 50.2 & 22.8 \\ 85 & 32.1 & 10.4 & 47.1 & 21.4 \\ 100 & 42.8 & 13.6 & 43.9 & 19.9 \\ 115 & 53.7 & 17.2 & 40.3 & 18.3 \\ 130 & 65.7 & 21.4 & 36.1 & 16.4 \\ \text { I45 } & 76.8 & 26.0 & 31.5 & 14.3 \\ 160 & 86.5 & 29.9 & 27.6 & 12.5 \\ 175 & 95.2 & 33.6 & 23.9 & 10.9 \\ 200 & 107.3 & 39.3 & 18.2 & 8.3\end{array}$

Series X. Vol. $\mathrm{NH}_{3}$ in System, $103.4 \mathrm{cc}$.

$\begin{array}{rrrrr}-20 & 3.7 & 1.2 & 102.2 & 46.4 \\ -10 & 4.8 & 1.5 & 101.9 & 46.3 \\ 0 & 6.4 & 2.0 & 101.4 & 46.1 \\ 10 & 8.7 & 2.6 & 100.8 & 45.8 \\ 21.4 & 12.0 & 3.8 & 99.6 & 45.3 \\ 30 & 16.2 & 5.2 & 98.2 & 44.7 \\ 40 & 23.8 & 8.0 & 95.4 & 43.3 \\ 55 & 36.6 & 12.0 & 91.4 & 41.6 \\ 70 & 54.4 & 17.8 & 85.6 & 38.9 \\ 85 & 73.9 & 25.3 & 78.1 & 35.5 \\ 100 & 92.6 & 33.3 & 70.1 & 31.8 \\ 115 & 108.9 & 41.3 & 62.1 & 28.2\end{array}$


Volume of ammonia

\begin{tabular}{lcccc} 
Temp. & Press. cm. Hg. & $\begin{array}{c}\text { In vapor } \\
\text { phase. } \\
\text { Series }\end{array}$ X (continued). & $\begin{array}{c}\text { Total } \\
\text { adsorbed. }\end{array}$ & $\begin{array}{c}\text { Adsorbed } \\
\text { per g. C. }\end{array}$ \\
I30 & \multicolumn{2}{c}{ (conting } & \\
145 & 125.2 & 49.2 & 54.2 & 24.6 \\
160 & 139.3 & 57.2 & 46.2 & 21.0 \\
175 & 150.9 & 64.3 & 39.1 & 17.8 \\
200 & 160.4 & 70.1 & 33.3 & 15.1 \\
& 173.1 & 78.3 & 25.1 & 11.4
\end{tabular}

Series XI. Vol. $\mathrm{NH}_{3}$ in System, $153.4 \mathrm{cc}$.

\begin{tabular}{|c|c|c|c|c|}
\hline-20 & 6.7 & 2.1 & I $51 \cdot 3$ & 68.8 \\
\hline-10 & 8.7 & 2.7 & I 50.7 & 68.5 \\
\hline o & I I. 4 & 3.6 & I 49.8 & 68.0 \\
\hline IO & 15.7 & $5 \cdot 1$ & 148.3 & $67 \cdot 4$ \\
\hline 20 & 22.2 & $7 \cdot 5$ & 145.9 & 66.3 \\
\hline 30 & 31.0 & 10.4 & 143.0 & 65.0 \\
\hline 40 & $43 \cdot 4$ & 14.2 & I39.2 & $63 \cdot 3$ \\
\hline 55 & $67 \cdot 3$ & $2 I \cdot I$ & $132 \cdot 3$ & 60.1 \\
\hline 70 & 94.2 & $34 . I$ & I I $7 \cdot 3$ & $53 \cdot 3$ \\
\hline 85 & I 20.9 & 47.8 & 105.6 & 48.0 \\
\hline 100 & 144.3 & $6 I .2$ & 92.2 & $4 I .9$ \\
\hline I I 5 & 162.9 & 73.0 & 80.4 & 36.6 \\
\hline 130 & 180.6 & 85.1 & 68.3 & 31.0 \\
\hline I 45 & I95.3 & 95.6 & 57.8 & 26.3 \\
\hline 160 & 207.2 & $104 . I$ & $49 \cdot 4$ & 22.4 \\
\hline I75 & $2 I 7 \cdot I$ & III. 8 & 41.6 & 18.9 \\
\hline 200 & 230.2 & 122.4 & 31.0 & $14 . I$ \\
\hline
\end{tabular}

Series XII. Vol. $\mathrm{NH}_{2}$ in System, $203.3 \mathrm{cc}$.

-20
-10

0

Io

20

30

40

55

70

85

100

I 5

130

I 45

I6o

I 75

200

-20
-10

0
10

20.7

\begin{abstract}
I I 5
I 4.3

I8. 9

26.3

37.6

53.3

72.3

104.3

I 36.8

I 66.5

I9I. 5

2 II. $O$

229.7

244.7

257.0

266.9

279.8
\end{abstract}

108.7

123.6

135.7

148.2

I 57.8

I 69.6

Series XIII
22.7

$27 \cdot 7$

36.8

5 I. 7

$72 \cdot 3$
3.7

4.6

6.3

9.1

12.7

18.0

25.7

39.8

56.7

76.4

94.0

\section{99.6}

198.0

197.0

194.2

190.6

I 85.3

I 77.6

I 63.5

I 46.6

126.9

$\operatorname{I09} \cdot 3$

94.6

79.7

67.6

55.1

$45 \cdot 5$

$33 \cdot 7$

8.0

9.3

12.7

17.6

26. I
249.4

248 . I

244.7

239.8

231.2
90.7

90.3

89.6

88.3

86.7

84.2

80.7

74.3

66.7

$57 \cdot 7$

49.7

43.0

36.3

30.7

25.1

20.7

I5. 3

I I $3 \cdot 3$

II 2.8

III. 2

IOg.O

I05. I 


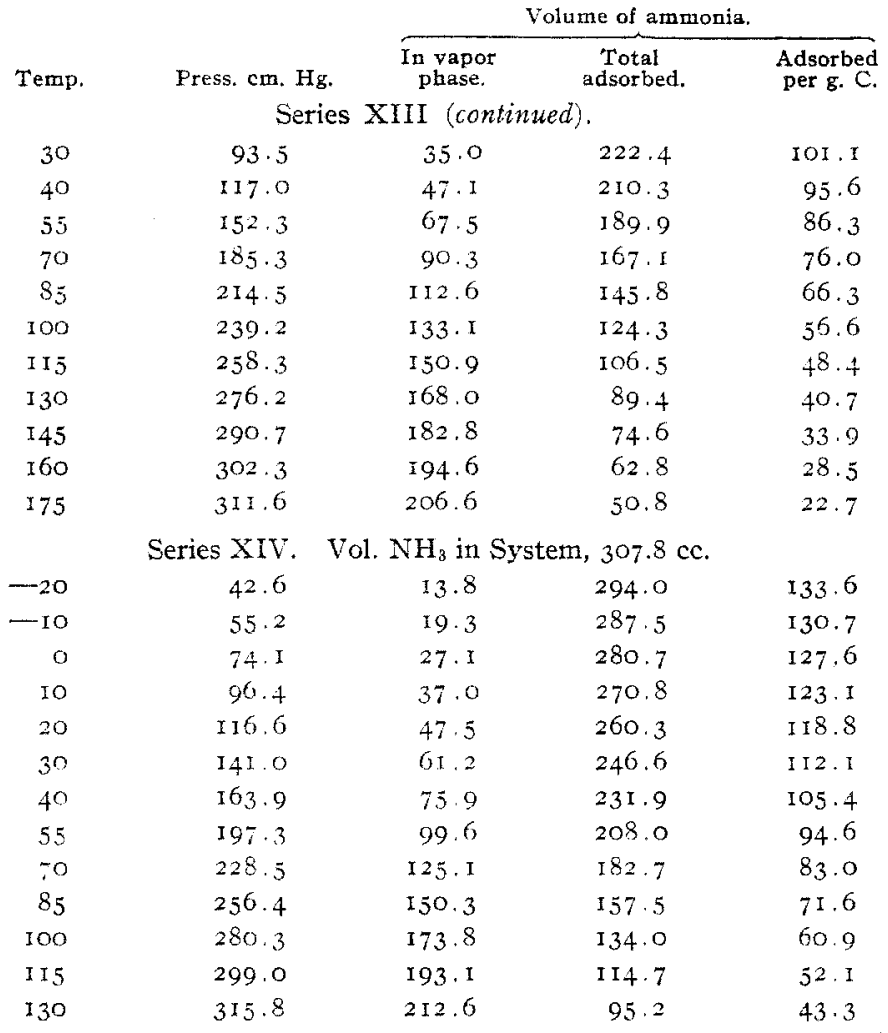

Series XV. Vol. $\mathrm{NH}_{3}$ in System, $386.1 \mathrm{cc}$.

$\begin{array}{rrrrr}-20 & 117.6 & 49.6 & 336.5 & 152.9 \\ -10 & 138.3 & 61.0 & 325.1 & 147.7 \\ 0 & 160.7 & 75.6 & 310.5 & 141.0 \\ 10 & 182.5 & 90.8 & 295.3 & 134.2 \\ 19.6 & 199.3 & 103.1 & 283.0 & 128.0 \\ 30 & 219.8 & 119.7 & 266.4 & 121.0 \\ 40 & 238.8 & 135.7 & 250.4 & 113.8 \\ 55 & 266.1 & 161.3 & 224.8 & 102.2 \\ 70 & 292.4 & 186.0 & 200.1 & 91.0 \\ 85 & 316.3 & 215.4 & 170.7 & 77.6\end{array}$

The pressure-temperature curves, together with the vapor-pressure curve of liquid ammonia, are shown in Fig. 4 ; the isotherms in Fig. 5.

Theoretical Considerations.

The relationship between amount of gas adsorbed by charcoal and the corresponding equilibrium pressure has been expressed by various exponential equations. The isotherm equation of Freundlich ${ }^{1}$ is in the form

$$
a_{t}=\alpha p_{t}^{1 / n},
$$

1 "Kapillarchemie," p. 94. 
in which $a_{t}$ represents the volume of gas adsorbed by one gram of charcoal at the temperature $t ; p_{t}$ the equilibrium pressure at that tempera-

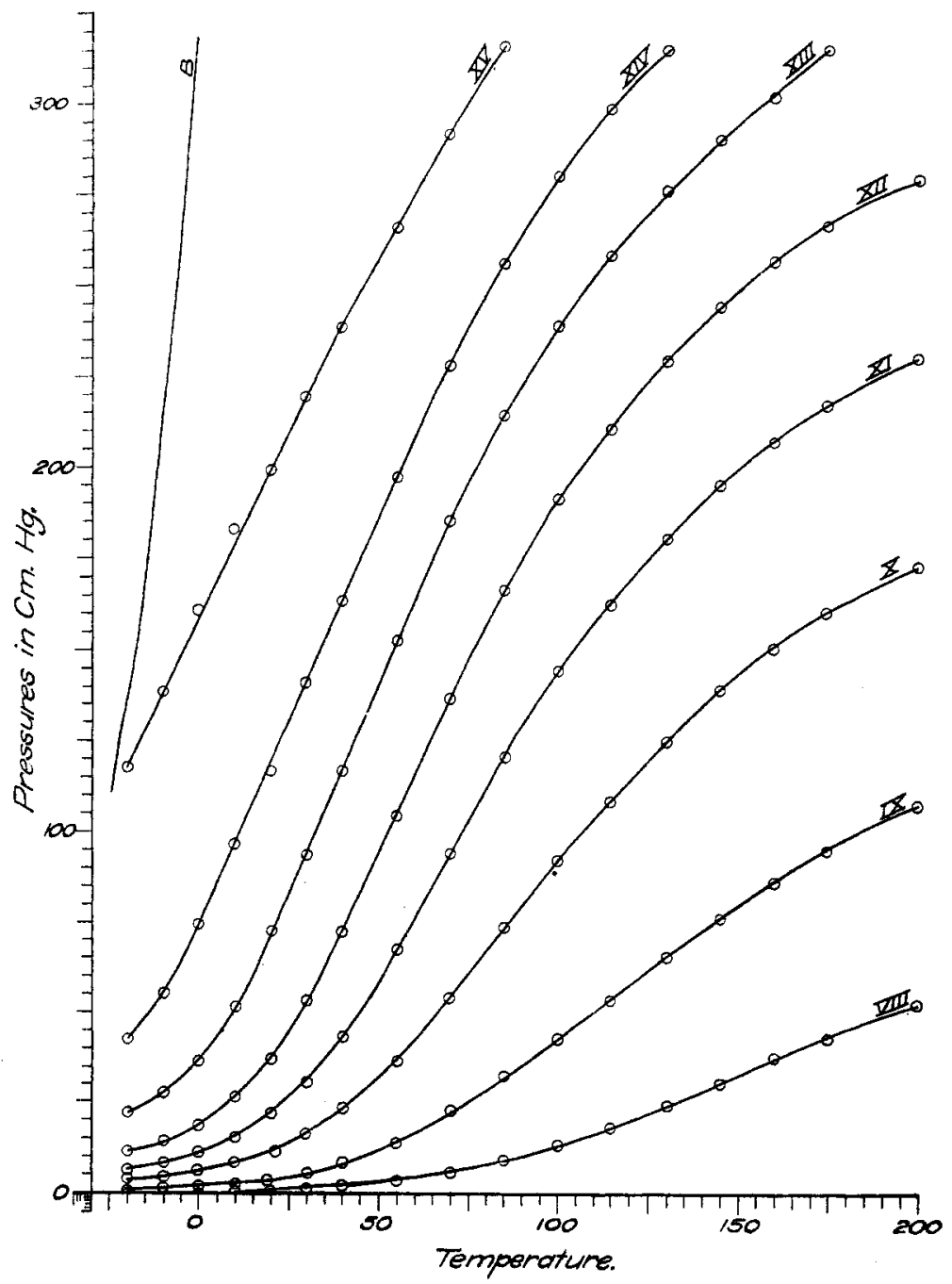

Fig. 4.

ture; $\alpha$ the volume of gas adsorbed at temperature $t$ under a pressure of one centimeter $(\log =0)$; and $\mathrm{I} / n$ is a constant which is equal to $\frac{d \log a}{d \log p}$, and which indicates the slope of the logarithmic curve. From the isotherm equation is derived the general equation applicable to all temperatures, 


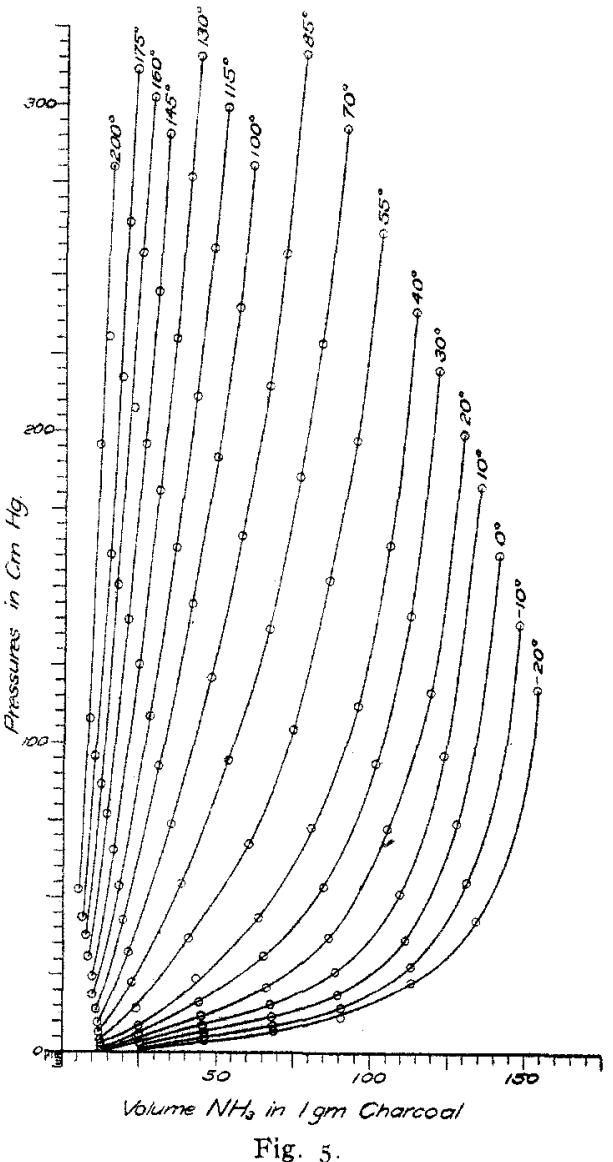

$\log a_{t}=\log a_{0}-(x-y \log p) t,{ }^{1}$ in which the constant $x$ is equal to $-\frac{d \log a}{d t}$ and $y$ to $\frac{d \mathrm{I} / n}{d t}$.

The validity of these expressions depends upon the constancy of the values of $\mathrm{I} / n \mathrm{de}$ rived from the experimental data at various pressure points in a given isotherm. Values obtained from the data of the present investigation, at selected isotherms, are found below.

The results are expressed graphically in Fig. 6, in which values for $\log a$ are plotted along the $y$ axis, those for $\log p$ along the $x$ axis. The points thus obtained should, in accordance with the theory, lie in a straight line, the slope of which represents $I / n$. From the nature of the logarithmic curve deviations to the left are magnified while those to the right are minimized in proportion to their true value. The results expressed above are not in agreement with the theory.

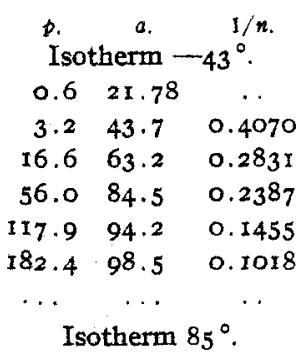

$29.2 \quad 8.3$

$58.1 \quad 15.0 \quad 0.852$

$\begin{array}{lll}124.4 & 22.4 & 0.5267\end{array}$

$\begin{array}{lll}184.0 & 26.4 & 0.4248\end{array}$

$\begin{array}{lll}249.5 & 28.9 & 0.2846\end{array}$

$293.5 \quad 32.9 \quad 0.7906(?)$
Carbon Droxide.

\begin{tabular}{|c|c|c|c|c|c|}
\hline \multicolumn{3}{|c|}{ Isotherm $0^{\circ}$. } & \multicolumn{3}{|c|}{ Isotherm $30^{\circ}$. } \\
\hline 2.4 & II. 4 & & 7.3 & 10.9 & \\
\hline 5.4 & 21.2 & 0.7562 & 16.8 & 19.9 & 0.7168 \\
\hline 22.6 & $4^{1} \cdot 3$ & 0.4732 & $56 \cdot 3$ & 36.4 & 0.4986 \\
\hline 62.6 & $5^{6.2}$ & 0.2956 & III .7 & $45 \cdot I$ & 0.3119 \\
\hline 135.7 & 66.8 & $0.223 \mathrm{I}$ & 183.0 & 53.4 & 0.3449 \\
\hline 191.3 & 73.1 & 0.2624 & 223.8 & 58.4 & 0.4324 \\
\hline $245 \cdot 0$ & $75 \cdot 7$ & 0.1446 & $28 \mathrm{I} \cdot 5$ & 61.8 & 0.2436 \\
\hline \multicolumn{3}{|c|}{ Isotherm I $30^{\circ}$. } & \multicolumn{3}{|c|}{ Isotherm $\times 45^{\circ}$} \\
\hline $52, I$ & 5.1 & . & 59.2 & $4 \cdot I$ & $\cdots$ \\
\hline 88.6 & 8.5 & 0.9739 & $97 \cdot I$ & 6.9 & I.077 \\
\hline 159.8 & 13.1 & 0.7319 & $\Upsilon 68.8$ & 10.6 & 0.7841 \\
\hline 219.7 & 14.6 & 0.3358 & 229.0 & II.I & 0,1414 \\
\hline $28 \mathrm{I}, \mathrm{I}$ & 16.2 & 0.4195 & 290.1 & 12.45 & 0.4490 \\
\hline $323 \cdot 7$ & 16.37 & 0.0783 & & $\ldots$ & . \\
\hline
\end{tabular}

${ }^{1}$ Freundlich, "Kapillarchemie," p. 103. 
Titoff ${ }^{1}$ determined values for $\mathrm{I} / n$ for pressures up to $70 \mathrm{~cm}$. at a greater number of pressure points than are here recorded for that pressure range. The values thus obtained, while they show a fair degree of agreement through relatively short distances, when taken as a whole deviate from a fixed value fully as much as those noted above. For the higher pressures with which this investigation is principally concerned there is, in general,

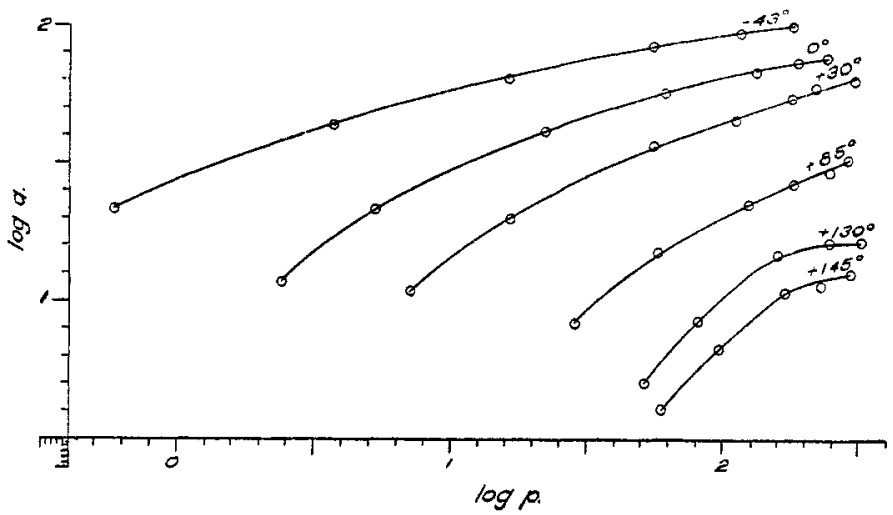

Fig. 6.

a rapid decrease in the magnitude of $1 / n$, a decrease which is shown on the diagram by a marked bending toward the $x$ axis of that part of the curve on the right.

The graphic representation is given in Fig. 7 . In the case of ammonia the values of $\mathrm{I} / n$ show less deviation for the theoretical values than in the case of carbon dioxide. The isotherms at $-20^{\circ}$ and at $0^{\circ}$ show in each case one point to be notably off the curve; the elimination of these points in the calculation gives values which are more concordant.

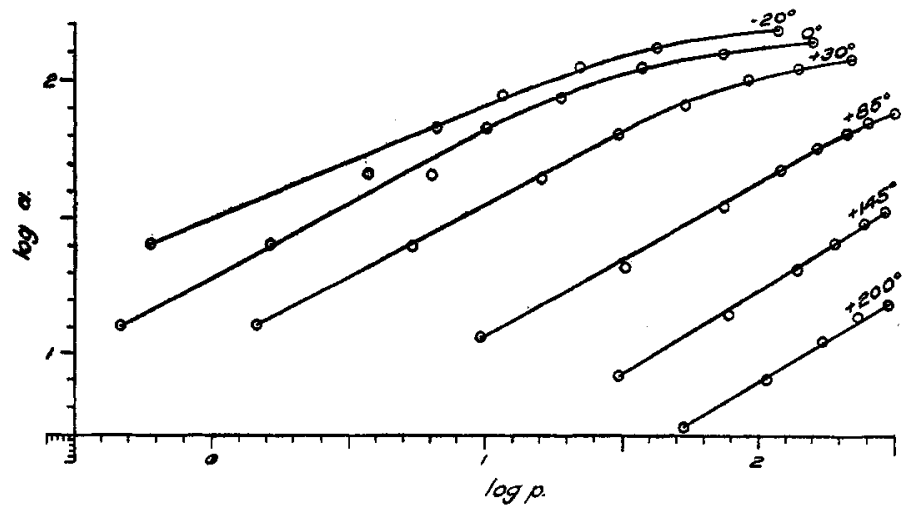

Fig. 7 .

${ }^{1}$ Loc. cit., p. 664 . 


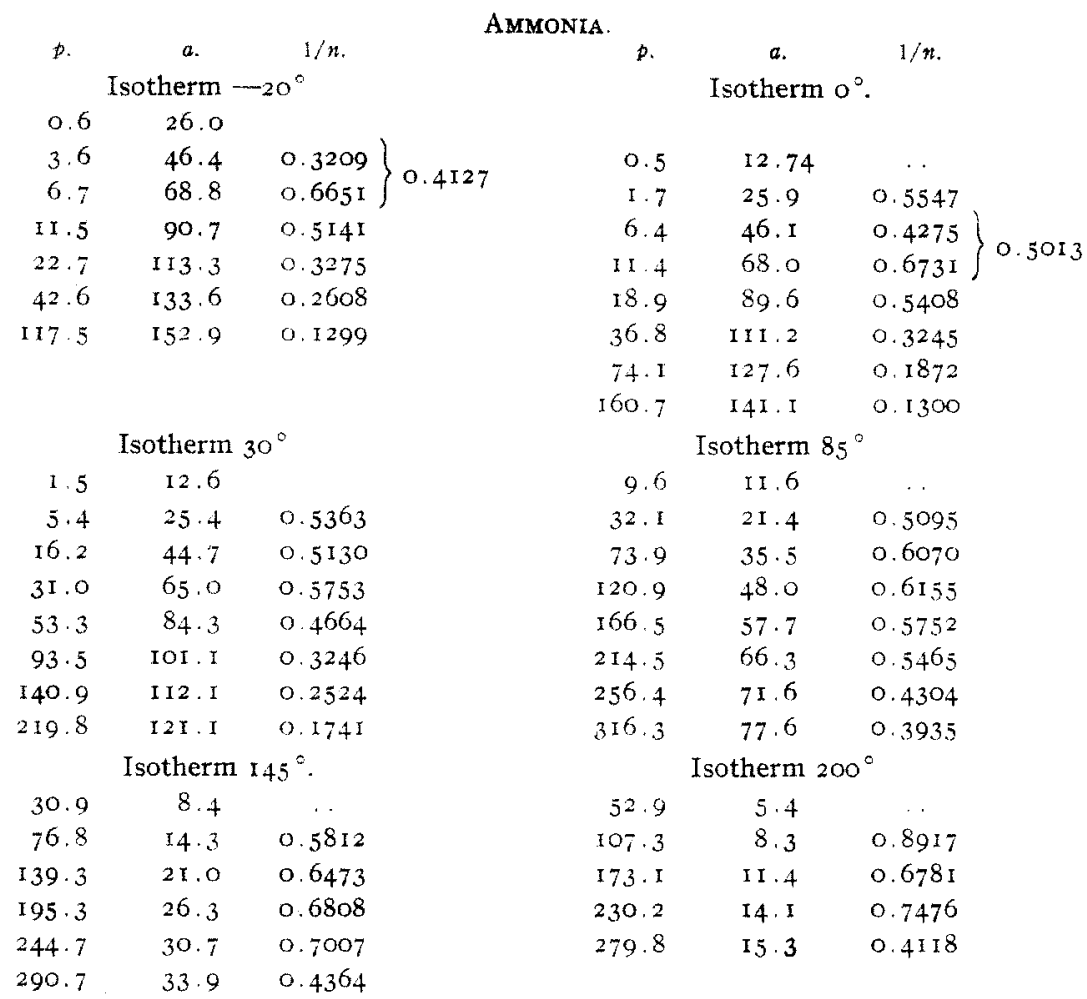

Through the lower pressure range $I / n$ is found to be relatively constant, but at higher pressures the decrease in the value of this expression is again marked, though the deviation is less striking at high temperatures than at low.

It may be concluded that in the case of carbon dioxide and of ammonia the decrease in the magnitude of $\mathrm{r} / n$ at high pressures is such as to make impossible the application of the equation of Freundlich to the calculation of volumes of gases adsorbed at these points. This conclusion is in harmony with the results of Schmidt, ${ }^{1}$ who found that the adsorption of acetic acid and of iodine by charcoal reaches a maximum arrived at asymptotically on increasing the concentration; and with the reasoning of Arrhenius, ${ }^{2}$ who has reached the conclusion from theoretical considerations that such a maximum limit exists also in the case of the adsorption of gases by charcoal.

In the paper of Miss Homfray ${ }^{3}$ it is stated that by plotting the logarithms of the percentage composition by weight of adsorbed gas in the

\footnotetext{
Z. physik. Chem., 74, 689 (1910).

2 "Theories of Solution," p. 62 (1912).

"Loc. cit., p. 149 .
} 
charcoal, determined at constant pressure, against the corresponding temperatures, points are obtained which fall on a straight line. In Fig. 8 this treatment is applied to data obtained in the present investigation. Curve $I$ is the isobar for $60 \mathrm{~mm}$. pressure; Curve III is a reproduction of the isobar obtained by Miss Homfray for the same pressure. It

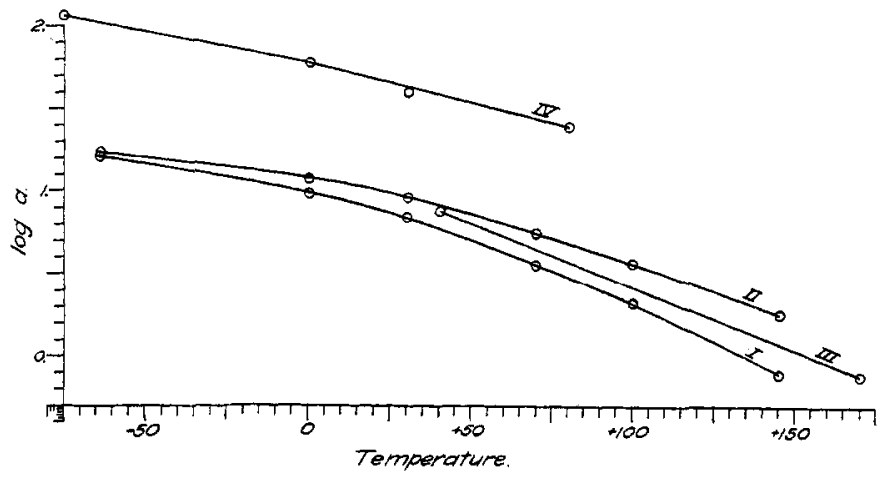

Fig. 8.

will be seen that while both curves are nearly straight within the limits of Curve III, at lower temperatures the isobar shows a marked tendency to bend toward the $x$ axis. Curve IV taken from the data of Titoff, confirms this conclusion. The ordinates in this case are the logarithms of volumes of gas adsorbed in one gram of charcoal and the pressure is $56 \mathrm{~cm}$. The curves are thus comparable and the same deviation is found to develop in the low temperature region. Curve II, an isobar at $150 \mathrm{~cm}$. drawn from data obtained in the present investigation, has the same form. It is thus evident that the principle set forth by Miss Homfray holds only within a limited region.

Few investigators at the present time consider that adsorption is due to chemical action between gas and charcoal. Nevertheless, in special cases there is some basis for this belief. Rhead and Wheeler ${ }^{1}$ assert that in the adsorption of oxygen by charcoal there is formed a substance to which they give the formuls $\mathrm{C}_{x} \mathrm{O}_{y}$. Upon being heated this hypothetical compound is supposed to break up into carbon dioxide and carbon monoxide.

$$
x \mathrm{C}+y \mathrm{O}=\mathrm{C}_{x} \mathrm{O}_{y}=u \mathrm{CO}+v \mathrm{CO}_{2} \text {. }
$$

It is an observed fact that the gases last mentioned are always present in the gas driven off from charcoal in which oxygen has been adsorbed. Upon the assumption that the theory of Rhead and Wheeler is correct, it is possible that the reaction formulated by them might proceed in the reverse direction at some point in the pressure region here investigated; that $\mathrm{C}_{x} \mathrm{O}_{y}$ might be produced by the action of carbon dioxide upon charcoal, and that evidence of its existence and possibly of its composition

1 J. Chem. Soc., 103, 64I (1913). 
might be obtained from a consideration of the pressure-temperature curves. Inspection of these curves (Fig. 2), however, does not justify such a conclusion. The formation of a compound or compounds of definite vapor pressures (the hypothetical $\mathrm{C}_{x} \mathrm{O}_{y}$ ) would be shown by a tendency of the pressure-temperature curves to merge into a single line in the region where the existence of suci a compound becomes possible; in other words, the system in this region becomes univariant. No such tendency is shown by the curves in the diagram; they are merely tracings upon a plane surface, and are in no wise different in character from the pressuretemperature curves derived from the ammonia adsorption (Fig. 4), a process in which there is no special reason to believe that chemical action is. involved. Therefore either $\mathrm{C}_{x} \mathrm{O}_{y}$ is composed of an infinite number of indefinite compounds of carbon and oxygen, varying progressively in composition, or, by far the more likely supposition, it is not formed at all under the conditions existing during these experiments.

Certain investigators of the process commonly called adsorption consider that the gas enters the structure of the charcoal so that the action is one of solution and absorption rather than one of true adsorption. Miss Homfray brings to the support of this theory evidence of the applicability to the charcoal-gas system of the Ramsay-Yourig principle, hitherto confined to the vapor pressures of liquids. Most observers, however, agree that equilibrium in such systems is reached quickly $\left(1 / 2^{-2}\right.$ hours), a fact which constitutes the most valid objection to the theory above stated. It seems most improbable that equilibrium should be reached in such a short period of time if the process were one of penetration of gas into the structure of the charcoal. Adsorption is most generally regarded, therefore, as due to surface action, to a condensation of the gas upon the surface of the charcoal, the surface tension of which is lowered by the presence of the gas. The evidence gained in the work here described is in accord with this view with one noteworthy exception. It was stated in the discussion of the equilibrium of the carbon dioxide that at low temperatures gas just introduced fails to reach equilibrium in a reasonable time, and that the equilibrium pressure at a given point, low in the temperature scale, obtained on a falling temperature is slightly different from that obtained at the same point on a rising temperature. A small portion of the gas seems to be conducting itself differently from the remainder. McBain, ${ }^{1}$ in an investigation of the adsorption of hydrogen at the temperature of liquid air, observed first a rapid decrease of the pressure which reached a maximum in a few minutes, then a slow decrease which continued for several hours. These phenomena he explained upon the assumption that the first sudden condensation of the gas is due to surface action adsorption, while the slower condensation is caused by a penetration of 
the gas into the material of the charcoal absorption, the former effect accounting for much the larger quantity of the gas. The combined process he termed "sorption." Although objection has been raised to this theory by other investigators on the ground that at ordinary temperatures no such action is observed, it nevertheless offers a tentative explanation of the abnormalities in equilibrium which were observed at relatively low temperatures in the present work. If we consider the absorption part of the process to be slow in its induction it is evident that freshly introduced gas will require a considerable time to enter the charcoal structure. Once there in quantities greater than are normal at a given temperature through action at a lower one it might leave its position, unless the supersaturated condition is relatively very great, with extreme slowness, and this might make possible two apparent equilibrium pressure values for each temperature, neither of which would represent the true point. The lag in the absorption part of the phenomenon in either direction (gas taken in or given out) may thus be the cause of the abnormalities described, while their disappearance at higher temperatures would be due to the practical disappearance of the absorption part of the process. This tentative explanation is open to numerous objection, but no better one suggests itself to the writer.

The view of the adsorption process most in harmony with the observations made in this investigation is as follows: Layers of gas, decreasing in density outward are condensed through the surface energy of the solid at the boundary surfaces. An equilibrium between free and adsorbed gas is thus established. Through a limited range increase of pressure causes increase in quantity of gas adsorbed in a fairly definite logarithmic ratio, but as the pressure increases beyond these limits the relative amount of adsorption becomes less, the density of the surface layers cannot be increased in the former scale; in other words, it becomes increasingly diffcult for additional quantities of gas to take their places in the already crowded surface region. A point should finally be reached at which increased pressure would cause no measurable increase in adsorption. In the same way the crowding effect causes a decrease in the relative 'amount adsorbed at constant pressure with a lowering of the temperature. At low temperatures the possibility exists that a small portion of the total gas in the solid phase is absorbed (dissolved) in the structure of the charcoal. This portion is relatively slow either to enter or to leave the charcoal structure. At higher temperatures this effect practically disappears.

\section{Summary:}

The equilibrium pressures of the system carbon dioxide-charcoal have been measured through the range $0-300 \mathrm{~cm}$., at twenty-one temperature points between $-64^{\circ}$ and $200^{\circ}$. The system ammonia-charcoal 
has been investigated through the same pressure range at seventeen temperature points between $-20^{\circ}$ and $200^{\circ}$.

Through a limited pressure range the degree of adsorption of gas is in fair agreement with the logarithmic isotherm equation of Freundlich, as has already been shown by previous investigators. At higher pressures (above $60 \mathrm{~cm}$.), the adsorption rapidly decreases, indicating that at each temperature a maximum is reached which cannot be increased by increase of pressure.

No evidence was gained of the formation of a chemical compound, such as that obtained by Rhead and Wheeler in the adsorption of oxygen by charcoal, by the reverse reaction of carbon dioxide upon charcoal at relatively high pressures.

The adsorption of carbon dioxide at low temperatures is attended by certain phenomena which give rise to the possibility that a small quantity of the gas is absorbed in the charcoal structure, in accordance with the theory of McBain.

In conclusion, the writer wishes to express his thanks to the authorities of Cornell University for their kindness in placing at his disposal the facilities of the chemical laboratory of that institution for the purposes of this investigation.

ITHACA, N. Y.

[Contribution from the Research Laboratory of the General Electric ComPANY, SCHENECTADY, N. Y.]

\section{THE CONSTITUTION AND FUNDAMENTAL PROPERTIES OF SOLIDS AND LIQUIDS. II. LIQUIDS. ${ }^{1}$}

Bx IRVING LANGMUTR.

Received May 23, 1917.

In Part $I,{ }^{2}$ reasons have been given for believing that all the forces acting between atoms (or group molecules) in solid bodies are fundamentally similar in character and are of the nature of so-called chemical forces. Thus, evaporation, condensation, solution, crystallization, adsorption, surface tension, etc., should all be regarded as typical chemical phenomena.

I The fundamental idea of the orientation of group molecules in the surfaces and in the interior of liquids as a factor of vital importance in surface tension and related phenomena, occurred to me in nearly its present form in June and July, 1916. During August surface-tension data for over 250 substances were tabulated and studied. Work on oil films began in June. As a result of this extensive work, clear ideas were obtained as to the orientation of molecules in the surfaces of liquids and the relation between the total energy $\gamma_{0}=\gamma-\mathrm{T} d \gamma / d \mathrm{~T}$ and the chemical constitution of such substances as benzene and its disubstitution products.

An account of this work was given in some detail in a paper read at the New York meeting of the American Chemical Society in September, 1916, and a short abstract was published in Met. Chem. Eng., 15, 468 (19I6). In this abstract only the more 